\title{
Human Dimensions Considerations in Wildlife Disease Management
}

Chapter 8 of

Section C, Techniques in Disease Surveillance and Investigation Book 15, Field Manual of Wildlife Diseases

Techniques and Methods 15-C8 



\section{Human Dimensions Considerations in Wildlife Disease Management}

By Kirsten M. Leong and Daniel J. Decker

Chapter 8 of

Section C, Techniques in Disease Surveillance and Investigation

Book 15, Field Manual of Wildlife Diseases

Edited by Katherine L.D. Richgels, Samantha E.J. Gibbs, and Margaret A. Wild

U.S. Geological Survey, U.S. Fish and Wildlife Service, and National Park Service

Techniques and Methods 15-C8 


\title{
U.S. Department of the Interior DAVID BERNHARDT, Secretary
}

\section{U.S. Geological Survey James F. Reilly II, Director}

\author{
U.S. Geological Survey, Reston, Virginia: 2020
}

For more information on the USGS — the Federal source for science about the Earth, its natural and living resources, natural hazards, and the environment-visit https://www.usgs.gov or call 1-888-ASK-USGS.

For an overview of USGS information products, including maps, imagery, and publications, visit https://store.usgs.gov.

Any use of trade, firm, or product names is for descriptive purposes only and does not imply endorsement by the U.S. Government.

Although this information product, for the most part, is in the public domain, it also may contain copyrighted materials as noted in the text. Permission to reproduce copyrighted items must be secured from the copyright owner.

Suggested citation:

Leong, K.M, and Decker, D.J., 2020, Human dimensions considerations in wildlife disease management:

U.S. Geological Survey Techniques and Methods, book 15, chap. C8, 21 p., https://doi.org/10.3133/tm15C8.

ISSN 2328-7055 (online) 


\section{Contents}

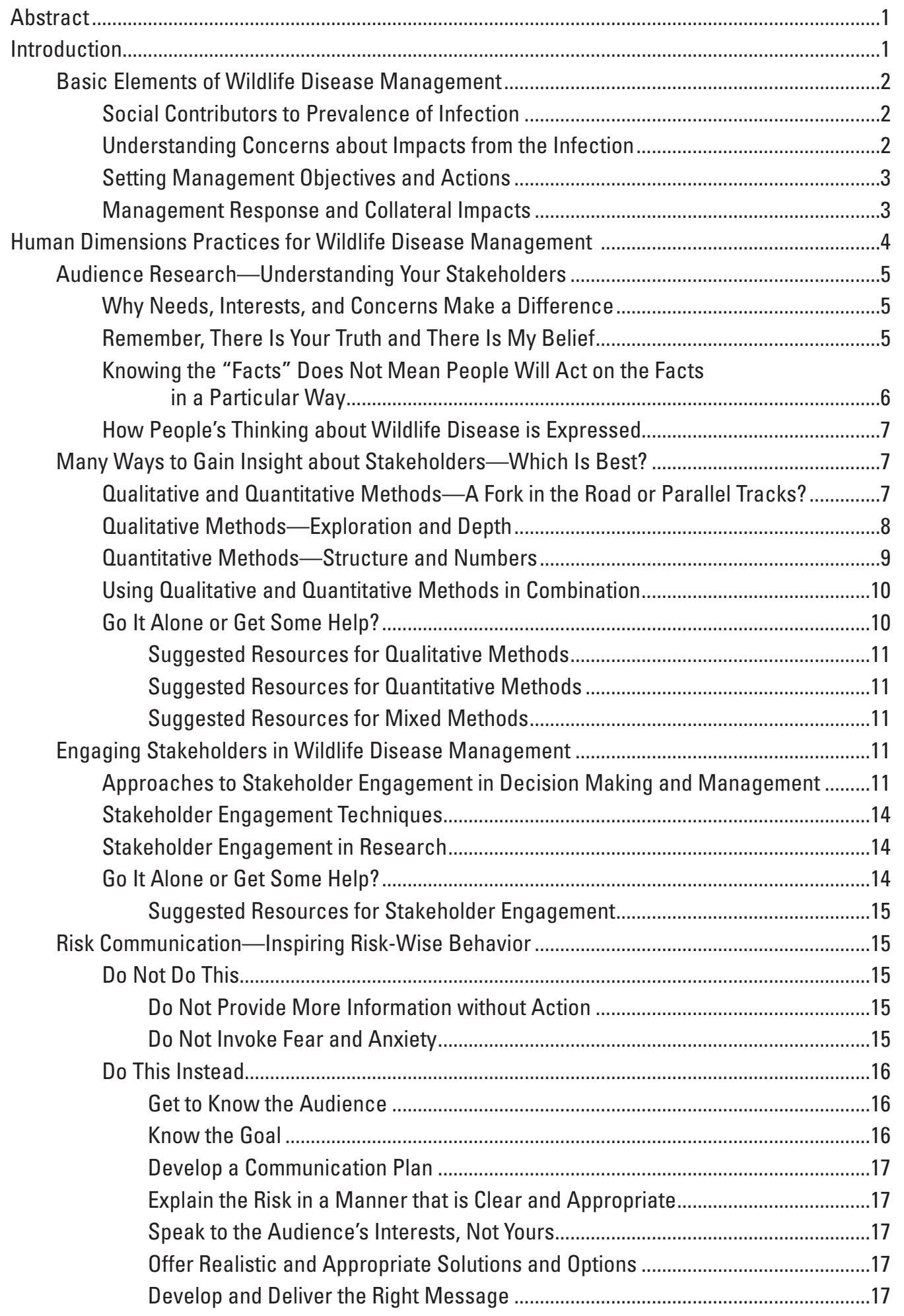




\section{Contents}

\begin{tabular}{|c|}
\hline 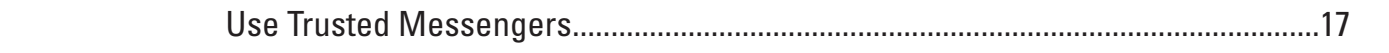 \\
\hline Respect Different Viewpoints and Acknowledge Emotions ......................................17 \\
\hline Communicating with the Audience \\
\hline Experiences with Wildlife \\
\hline Reactions to Wildlife Disease \\
\hline Framing the Conversation \\
\hline $\begin{array}{l}\text { Be Prepared—Be Prepared to Avoid Contact with Wildlife or } \\
\text { between Domestic and Wild Animals.............. }\end{array}$ \\
\hline 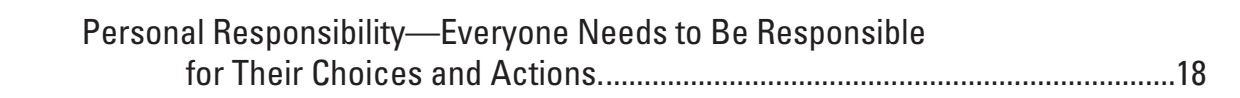 \\
\hline 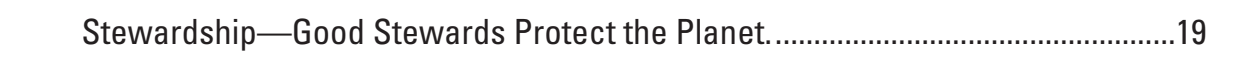 \\
\hline $\begin{array}{l}\text { Working Together-Communities Working Together Can Reduce Risks } \\
\text { from Wildlife Disease. }\end{array}$ \\
\hline Go It Alone, or Get Some Help? \\
\hline Suggested Resources for Risk Communication \\
\hline id Conclusion \\
\hline Cited \\
\hline
\end{tabular}

\section{Figures}

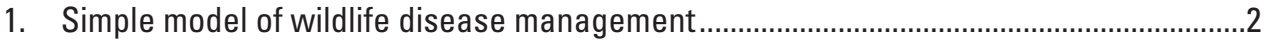

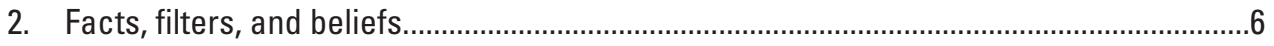

3. Stakeholder engagement strategy and relative decision-making influence of stakeholders compared to the natural resource management agency.

\section{Tables}

1. Areas of focus for qualitative and quantitative research............................................

2. Spectrum of approaches to stakeholder engagement in decision making .....................13 


\title{
Human Dimensions Considerations in Wildlife Disease Management
}

\author{
By Kirsten M. Leong ${ }^{1}$ and Daniel J. Decker ${ }^{2}$
}

\section{Abstract}

In 1943, Aldo Leopold observed that the real problem of wildlife management is not how to handle wildlife, but how to manage humans. As with any other aspect of wildlife management, social sciences can improve understanding the human dimensions of wildlife disease management (WDM). Human activities have accelerated the emergence of wildlife diseases, and human concerns about the ecological, social, and economic impacts of wildlife diseases and their management have led to diseases becoming headline-worthy public issues. This chapter provides guidance to help front-line professionals understand and address the public's perspectives and behaviors relevant to WDM. This chapter focuses on practical needs of wildlife disease managers who have to consider and interact with specific stakeholders and the broader public. The chapter does not dive deeply into social science; instead it briefly reviews some concepts that are most relevant to WDM. The chapter also suggests where to look for assistance and additional resources for further reading. Following brief introductory comments, the chapter is organized around a simple model of the general process for WDM. It addresses three key areas where social science can assist in WDM-audience research to understand stakeholders; engaging stakeholders in wildlife disease management; and using risk communication about wildlife diseases and disease management to inspire risk-wise behavior.

\section{Introduction}

More than two decades ago, Wobeser (1994, p. 134) described the following predominantly human-centered reasons for management of wildlife disease (emphasis added):

- disease has a real or perceived deleterious effect on populations of wildlife valued by humans;
- presence of disease in wildlife is a real or perceived threat to human health; and

- presence of disease in wildlife is a real or perceived threat to health of domestic animals, such as livestock and pets.

In addition, as noted in chapter A1 of this field manual (Friend, 2015), most wildlife disease management (WDM) challenges are not purely biological; they are often socially derived, with human ecology and behavior playing a large role. In fact, WDM typically is being influenced by and attempting to influence the sociocultural and economic system in which WDM is embedded. Thus, WDM is pursued within complex social-ecological systems where the human aspects of these systems are often drivers of problems and potential means to their solution.

As indicated by Wobeser's reasons for WDM, understanding how stakeholders perceive the disease management system is crucial in crafting effective management responses (Wobeser, 1994). Applied social science can improve empirical understanding of how human beliefs, attitudes, norms, and associated risk perceptions affect stakeholder concerns and responses in the WDM system. Well-designed stakeholder engagement processes can provide additional insights. These processes also can identify opportunities to collaborate with stakeholders to improve understanding, help clarify misperceptions, and even implement solutions. Throughout the management process, risk communication should result in risk-wise behavior rather than in human behavior that exacerbates an outbreak.

This chapter provides an overview of core concepts in each of these areas. The chapter is organized around a simple model of the general process for WDM. The following three key areas where social science can assist in these human dimensions of WDM are addressed: (1) audience research to understand stakeholders, (2) engaging stakeholders in WDM, and (3) using risk communication about wildlife diseases and disease management to inspire risk-wise behavior. Available sources of assistance are provided for each of these areas.

${ }^{1}$ National Oceanic and Atmospheric Administration.

${ }^{2}$ Cornell University. 


\section{Basic Elements of Wildlife Disease Management}

Because human values are embedded in wildlife disease issues and the approaches taken for their management, WDM requires understanding the values underlying people's concerns about wildlife disease, particularly effects on stakeholder tolerance of the impacts of wildlife diseases and social acceptability of management actions to address such impacts. The imperative to consider the affected publics, or "stakeholders" (that is, people who significantly affect or are significantly affected by wildlife disease or its management) was reinforced several years ago in an exercise where wildlife disease specialists and managers addressed the following question: "When a wildlife disease issue arises or is anticipated, what suite of factors needs consideration?" Exploration of that question revealed that human dimensions considerations were present throughout many parts of the WDM process (Decker and others, 2006).

A basic schematic of WDM, modified from Decker and others (2006), aids in the effort to focus on human dimensions important to management of wildlife disease. In a simple model (fig. 1), WDM has the following three components: (1) prevalence of infection causing disease in wildlife (stimulus or cause of professional and public attention); (2) concerns about impacts from the infection (reaction to/assessment of the stimulus), which may differ between wildlife disease professionals and the public as well as among different segments of the public; and (3) management objectives and actions to address the infection or people's perceptions of the impacts of infection (response to reaction), or both.

\section{Social Contributors to Prevalence of Infection}

Wildlife disease managers often start by trying to understand the prevalence of the infection. Foundational knowledge about disease biology is crucial in identifying a management approach. However, the biology of an outbreak can be affected by stakeholder responses to the disease. For example, whitenose syndrome (WNS) is a fungus that kills bats while they hibernate and may be spread in part by people who transfer the spores on their clothing or caving equipment. If cavers do not understand that contaminated equipment may inadvertently contribute to disease spread or if the disinfection process is too confusing or inconvenient, cavers may accelerate the spread of WNS to uninfected caves. Closer to home, how people maintain their backyards can also influence the infection patterns of West Nile virus, by increasing mosquito populations through standing water (for example, in plant pots), and by increasing concentration of birds and facilitating survival of infected birds through provisioning at bird feeders (Bradley and others, 2008). Considering the social factors can help alleviate or anticipate potential human activities that exacerbate infection prevalence.

\section{Understanding Concerns about Impacts from the Infection}

Concerns about wildlife disease are based mainly on wildlife disease managers' (that is, wildlife disease specialists' and other wildlife professionals') and stakeholders' beliefs that the infection has led to undesirable impacts or has potential to do so. Three primary categories of concern are identified

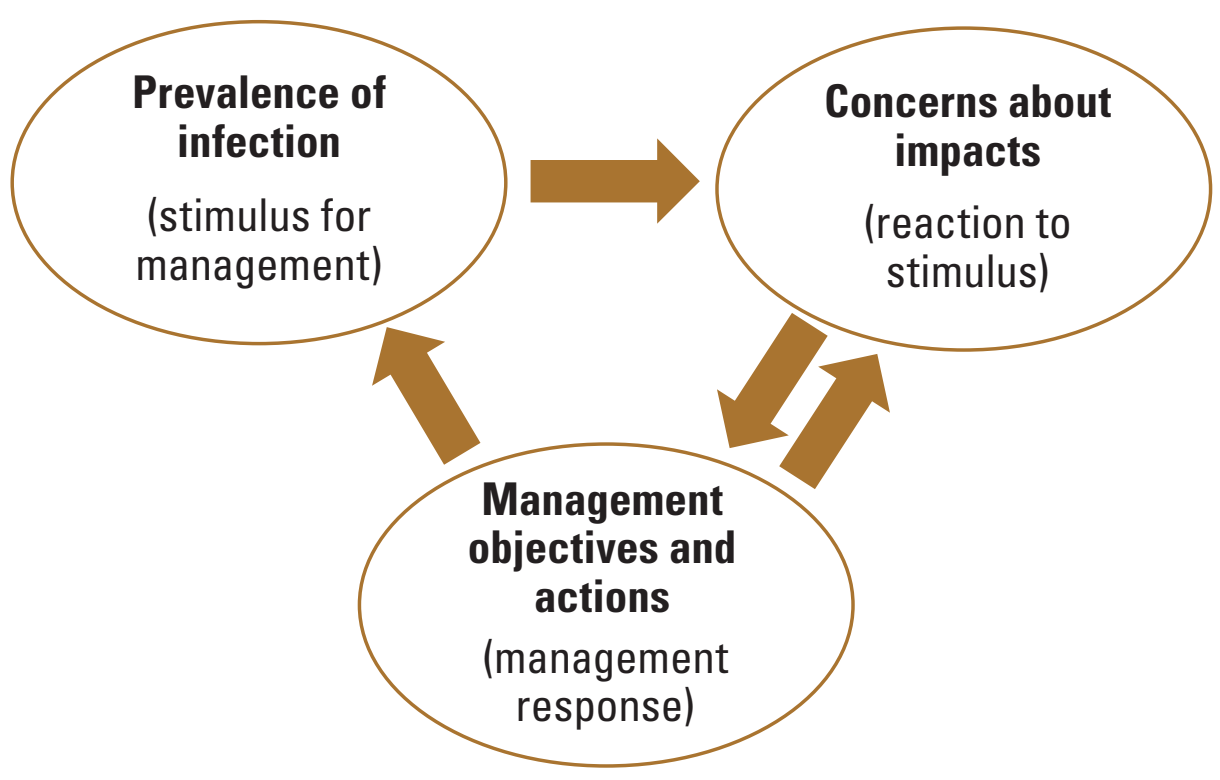

Figure 1. Simple model of wildlife disease management. Figure modified from Decker and others (2006). 
in the Decker and others (2006) model, much like the elements of WDM described by Wobeser (1994). These categories are risks to the health of (a) humans; (b) livestock, pets, and domestic animals; and (c) wildlife and the ecosystem or biotic community that support wildlife. Professional opinion usually is developed by scientific assessment of impacts, with a focus on determining the measurable risks related to prevalence, severity, and morbidity/mortality. These impacts are often referred to as the "hazard" dimensions of risk (Sandman, 1987). Public perceptions of risks are often affected by additional considerations (Slovic and others, 1979), sometimes termed "outrage" dimensions (Sandman, 1987). For wildlife diseases, these outrage dimensions can include social and economic impact on the domestic animal industry (for example, via foreign animal diseases, such as avian influenza or footand-mouth disease). Other outrage concerns may include who is affected, whether the risk is natural or manmade, or feelings of dread evoked (Slovic and others, 1979). In addition, these concerns can be amplified by media coverage and even by management activities (Kasperson, 1992).

Thresholds for public tolerance of wildlife disease impacts also can be context specific (that is, likely to differ from one disease to another, from one location to another, from one time to another, and among different stakeholders in the same locality with respect to the same disease outbreak). Some diseases also may have greater consequences for certain segments of stakeholders. For example, in 2011 an unusual mortality event in ice seals and walrus in Alaska was concerning to conservationists who worried about impacts to pinniped populations; however, community members and subsistence hunters who relied on these animals for food desired more immediate answers regarding whether animals were safe to eat.

Differences in concerns and acceptability or tolerance of impacts among stakeholders (their capacity to accept or tolerate the perceived consequences of disease) can be better understood through systematic social science inquiry. Gaining a better understanding of the range of social factors that give rise to stakeholder concerns is crucial to be able to address and speak to these concerns in a way that is meaningful to those affected by the disease.

\section{Setting Management Objectives and Actions}

In response to professional and public concerns, WDM objectives are developed that describe the desired outcomes of interventions. Developing objectives and deciding how to achieve them are processes occurring amid continuous agency evaluation of the situation, including understanding stakeholder concerns about the disease and perceptions of management response. Agencies evaluate and interpret the following contextual factors with respect to their effort in WDM: agency mandate/policy with respect to wildlife disease; broad public and specific stakeholder perspectives about risk presented by the disease and appropriate management response to the disease; science that can be brought to the problem; politics surrounding a wildlife disease situation; and aggregate professional judgment and its prudent application (that is, the interpretation of science and politics for a particular situation).

Because stakeholders often have different beliefs, attitudes, norms, and risk perceptions from managers, engaging stakeholders in the processes of determining appropriate objectives and actions can be useful. Stakeholder engagement, which can affect the acceptability of the management action, can be approached in many ways. For example, engaging stakeholders in considering how to manage hyperabundant Odocoileus virginianus (white-tailed deer) populations in national parks revealed that the public did not approve of wasting the meat from culled animals. Parks within the range of chronic wasting disease (CWD) included CWD testing in the parks' protocols and partnered with state agencies so the meat could be donated to local food pantries.

Evaluation of the contextual factors against the pros and cons of various stakeholder engagement approaches can ensure that necessary voices are appropriately included in determining the management response.

\section{Management Response and Collateral Impacts}

WDM objectives can be achieved in more than one way and with different public reactions to the methods used. Reactions to management responses can feed back into the system and have unintended consequences, or collateral impacts (Decker and others, 2006), on concerns or disease prevalence. For example, the 2002 detection of CWD in free-ranging deer in Wisconsin led to concerns among professionals and the public about the risk of widespread, high rates of mortality in the deer population and the potential for infection of livestock or humans. Although professionals and the public shared the concern about CWD, when managers began reducing deer populations to control the spread of CWD, hunters misinterpreted the message, lost trust in the agency, and reduced hunting efforts, which made the spread of CWD more difficult to control (Heberlein, 2004). Even pursuit of the modest objective of determining prevalence of an infection can involve unpopular actions. For example, States with surveillance programs for CWD (Illinois, New York, Michigan, and Wisconsin) required killing many white-tailed deer to examine their brains, which resulted in public backlash, even though hunters participated in the process. People's perceptions of management activities are filtered through processes such as judgments about human health risk, animal welfare, and trust in agency actions, which can have great bearing on support or opposition to a WDM program.

Management responses also may include actions directed at inspiring risk-wise behavior, which are intended to affect concerns and disease prevalence. These actions can include targeting wildlife workers, such as those described in chapter $\mathrm{C} 2$ of this field manual, "Safe Work Practices for Working with Wildlife" (Buttke and Taylor, in press). In addition, experts and the public may have different perceptions of risk, 
which can be problematic if members of the public do not take risks seriously enough and fail to protect themselves, or if they overreact to risks and demand inordinate management attention. Even in face-to-face exchanges, communication leading to mutual understanding of risks between wildlife disease managers and stakeholders can be elusive. Because experts and the public may focus on different aspects of risk, talking past each other is easy unless special attention is paid to listening to the things that others care about. Such dialogue may change the way that concerns are thought about and subsequent responses, both on the part of the public and managers. Elements of risk that managers perceive as important (or easily measurable) possibly are not what the public perceives as important; therefore, being aware of this difference helps to ensure that interactions between specialists and the public focus on, at least initially, what matters most to the public.

In these situations, expertise from the field of risk communication may be especially helpful. In WDM, risk communication is intended to provide the public with information they need to understand and make informed judgments about disease risks to the health and wellbeing of the people, animals, places, and practices they care about (Morgan and others, 2002). Effective risk communication is based on understanding risk perceptions and communication preferences of target audiences and provides information aimed at preventing, solving, or mitigating the disease risk and avoiding unintended social amplification of risks. For example, when CWD was discovered in a captive white-tailed deer facility in New York in 2006, the coordinated communication efforts of the State health, agricultural, and wildlife agencies were focused on avoiding amplification of risk by the "rumor mill." These agencies consistently informed the public that no risks of the disease being transmitted from deer to humans and livestock were known. However, agency staff regularly were seen (including on television news) using the highest level of personal protective equipment when handling the deer (for example, hazmat suits), which could imply high risk of human transmission. What managers may view as taking a precautionary approach to staff health risks may be seen by the public as contradicting the official agency position. Risk communicators can help identify potential for this type of mixed messaging.

Management responses will be more effective when managers include empirical understanding of audience concerns and appropriate stakeholder engagement in the design of management responses. This information can help anticipate and address any potential collateral impacts of management. In addition, risk communication practices can improve design of management responses intended to affect people's concerns or behaviors that might in turn affect disease prevalence.

\section{Human Dimensions Practices for Wildlife Disease Management}

Some of the ways that the social sciences can contribute to WDM are identified in the "Basic Elements of WDM" section. More detail and guidance on social science theories, methods, and practice are provided in the rest of this chapter. The information can help address the following three most important human dimensions matters for wildlife disease managers:

- Audience research to understand stakeholders, including their beliefs, attitudes, and norms and the risk perceptions arising therefrom when confronted with wildlife disease.

- Engaging stakeholders in wildlife disease management to better understand their concerns, improve policy, and design an effective management response that will gain public approval (or at least consent) and, therefore, be durable.

- Using risk communication about wildlife diseases and disease management to inspire risk-wise behaviors that reduce human contribution to disease spread, increase personal protective behaviors, and avoid misunderstandings about WDM intentions.

For each area, key management considerations are discussed, and techniques are suggested for handling the human dimensions. Advice is offered as to what can be done alone and when to seek help from experts. Some techniques are straightforward and do not require training. However, consulting with social scientists and others with expertise in audience research, stakeholder engagement, risk communication, or other specializations is advised in many instances. Specialists in these areas can design and test strategies aimed at affecting people's knowledge, attitudes, and behaviors or are adept at facilitating public discourse and gaining public input on contentious topics. Collectively, these activities provide foundational understanding to the "Risk Communication" component identified as essential in all stages of risk analysis in the Manual of Procedures for Wildlife Disease Risk Analysis published by the International Union for Conservation of Nature and World Organisation for Animal Health (JakobHoff and others, 2014). The risk communication component was not discussed at length in that manual because technical aspects related to understanding risk perception and risk communication were beyond the scope of the document. The following sections address this topic in more detail. 


\section{Audience Research-Understanding Your Stakeholders}

President Abraham Lincoln once observed “... public sentiment is everything. With public sentiment, nothing can fail; without it, nothing can succeed" (Zarefsky, 1994, p. 23). President Lincoln understood a basic truth in our democracysupportive public opinion is key to effective public work. This statement is true in all areas of government endeavor and particularly so for management of public trust resources, such as wildlife.

Understanding probable public reactions to WDM requires knowledge of people's beliefs, attitudes, preferences, and expectations (often thought of as "opinions," which drive public sentiment) with respect to risks from wildlife disease and management actions. Inquiry to uncover these human traits offers managers insight about the best ways to engage stakeholders in management and design communication that influences their risk perceptions and behaviors. Though not a perfect predictor, understanding drivers of public sentiment, such as norms and values, contributes to anticipating human behavior. This section summarizes some of the reasons to attend to these human dimensions, taken mainly from Decker and others (2017). This section also describes the social science methods most relevant to WDM that can be used to gain an empirical understanding of public sentiment.

To be relevant, valued, and a priority, a topic has to have salience to people's basic needs or compelling aspirations, which are reflected in their recognition or expression of needs, interests, and concerns. Among these needs and aspirations, a high priority for most people seems to be comfort and convenience - as a society people seem consistent in placing lifestyle considerations ahead of most everything else. Understanding which needs, interests, and concerns are salient to lifestyle goals of segments of society provide clues to strategic associations between WDM foci and the prevailing needs, interests, and concerns of those segments. So, a question to ask, "to which coattails can WDM attach if the aim is to raise WDM as a priority?"

\section{Why Needs, Interests, and Concerns Make a Difference}

People typically shape the social-ecological system that provides context for WDM by the way that they think about and place value on various elements of the system. Even when "the public interest" in wildlife disease and disease management takes the tangible forms of regulations, laws, and public policies (that is, the formal or legal expression of public interest in management of wildlife disease), the variability in people's attitudes about the species of wildlife involved, perceptions of the nature and extent of threats to their personal health or that of others, and attitudes about management of wildlife (in general and with respect to specific management techniques, such as killing animals) can create complications for managers.
Often, differences in people's interests and concerns (beliefs and attitudes, typically expressed as positions, opinions, preferences, and expectations) with respect to a WDM situation appear incompatible and irreconcilable. This condition becomes evident, for example, when conflicting interests among stakeholders create tension during planning for disease management. Tension typically surfaces when planning raises questions such as the following:

- Which wildlife should be protected at all costs and which wildlife is less important?

- Why does management of this disease matter and to whom?

- What WDM goals are desired and which actions are acceptable to use in a particular situation?

- How might WDM actions affect individual's livelihoods, safety, recreation activities, or the local economy?

- Who gets to decide whether, how, and when to proceed with WDM in a particular situation?

Opposing views on the appropriate answers to such questions can be expected; the salience of the issue and degree of divisiveness depends on how wildlife disease or its management affects the people involved. Understanding interests and concerns of those individuals who hold various views or positions, how energetically they will work to have their views prevail, and what information needs they have can all be valuable intelligence to gather when planning and implementing a WDM program.

\section{Remember, There Is Your Truth and There Is My Belief}

Human behavioral science provides insights into the formation of risk perceptions. The essence of human behavioral science is captured by three concepts - beliefs, attitudes, and norms. Relationships between these concepts will be illustrated using the case of toxoplasmosis and outdoor cat management. Beliefs relevant to a disease situation include "facts" in the usual, objective sense, but also include other inputs (such as opinions of others or personal experiences considered analogous to the situation at hand) that affect the way people think about the facts, including the importance that people place on specific facts in the context of WDM. For toxoplasmosis management, key facts are: toxoplasmosis infects many domestic and wildlife species; the disease organism, Toxoplasma gondii, is a microscopic protozoan parasite that reproduces sexually only in felines; toxoplasma oocysts are released into the environment via cat feces and can be ingested by other animals leading to a suite of ailments or death; and, toxoplasmosis has been shown to negatively impact threatened and endangered wildlife populations (Aguirre and others, 2019). Beliefs are what people perceive 
to be true, which in turn affect their attitudes and intended behaviors. For example, many wildlife managers believe that reducing toxoplasmosis risk to wildlife is crucial. Attitudes are evident when people judge effects of a disease as being favorable or unfavorable, good or bad. Wildlife managers typically hold negative attitudes towards allowing outdoor Felis catus (domestic cats) to kill wildlife, whether directly through predation or indirectly via toxoplasmosis. Norms are beliefs about standards of behavior with respect to what people should do or what most people are doing. Social norms are defined by shared beliefs about the acceptability of a condition or an action; social norms are highly situational. For wildlife managers, a commonly expressed norm is that outdoor cat populations should be reduced to protect wildlife. In addition, culling should be included as a potential management tool, to be considered in conjunction with other options, such as adoption, depending on the situation. Normative beliefs can greatly affect public acceptability of wildlife management actions. For example, although culling is an accepted wildlife management technique to prevent outbreaks, culling is unacceptable for many segments of the public who may have other normative beliefs, such as beliefs that culling should not be used for species that are pets or that welfare of individual cats should be the main concern of outdoor cat management. This disconnect between wildlife managers and people whose focus is well-being of feral and outdoor cats (that is, not wildlife) has resulted in decades of conflict on how to reduce impacts from outdoor domestic cat populations and other wildlife management issues.

\section{Knowing the "Facts" Does Not Mean People Will Act on the Facts in a Particular Way}

Do not make the error of thinking that by providing "facts," the public will accept the facts as truth and act the way that is expected with these facts in hand. This information deficit approach is a known fallacy, as perceptual and cognitive filters intervene (National Academies of Sciences, Engineering, and Medicine, 2017). Existing beliefs, attitudes and social norms influence how new information is processed, interpreted, and integrated into an individual's way of looking at a WDM situation (fig. 2).

Unfortunately, these cognitive traits vary from one group of people to another, so inquiry is often needed specific to a human population of interest and the WDM situation. Individual's beliefs, attitudes, and norms are influenced by those prevailing in the societies in which the individual lives and interacts. How people behave as members of a group and how they interact with one another differs within a society. Significant social differences occur among regions of the United States and even within states (for example, urban compared to rural communities). The complexity of wildlife management is created mostly because the enterprise operates in a social context characterized by this diversity of beliefs, attitudes, and norms and related interests, concerns, and risk perceptions with respect to management outcomes and methods. For example, stakeholders and wildlife managers in Washington State held different beliefs regarding the cause of elk hoof disease, a condition in which hooves of affected elk overgrow

\begin{tabular}{|c|c|}
\hline $\begin{array}{c}\text { Cognitive } \\
\text { inputs }\end{array}$ & $\begin{array}{c}\text { Influence of existing beliefs, attitudes, and norms } \\
\text { (filters) on cognitions }\end{array}$ \\
\hline
\end{tabular}

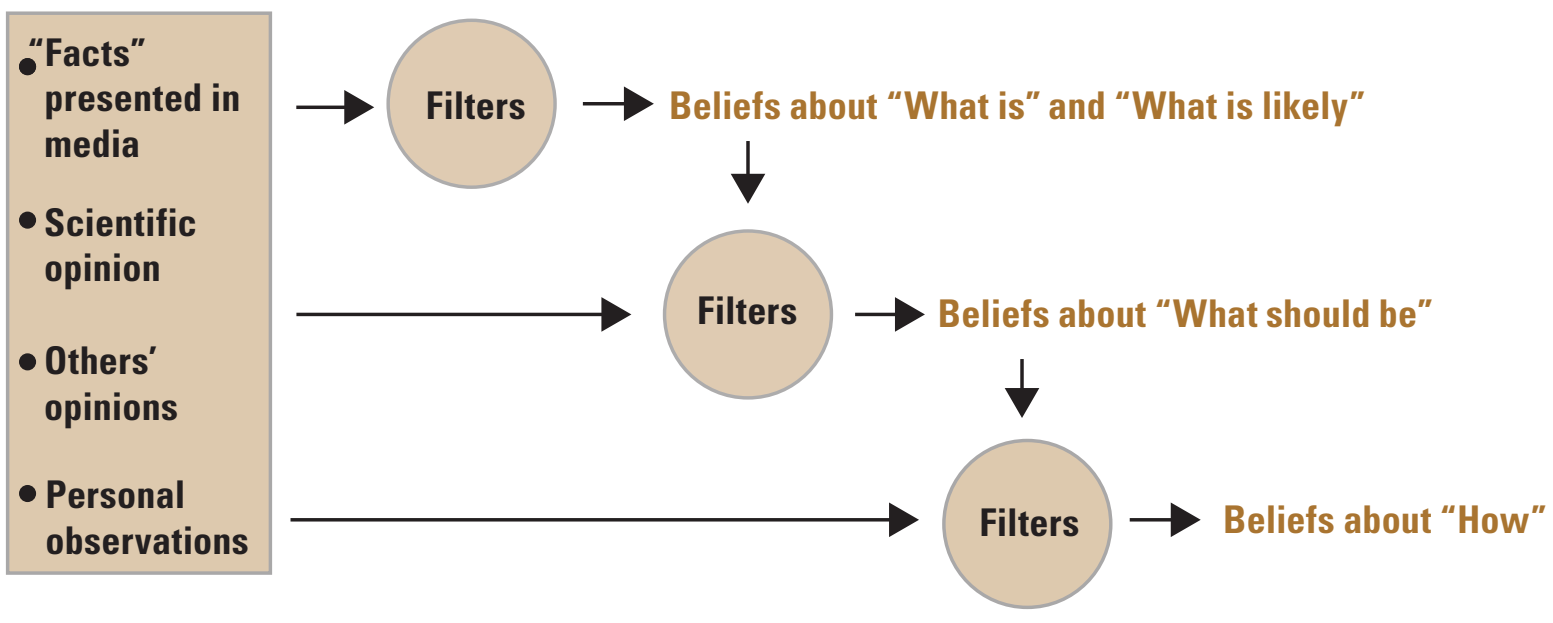

Figure 2. Facts, filters, and beliefs. Figure modified from National Park Service (2014). 
and may be sloughed. Despite peer-reviewed articles implicating treponeme bacteria (Clegg and others, 2015), some vocal stakeholders discredited the finding and adhered to alternative beliefs due at least in part to lack of trust in the management agency (for example, see http://jongosch.com/category/ elk-hoof-disease/page/3/).

\section{How People's Thinking about Wildlife Disease is Expressed}

People's concerns about wildlife disease frequently are reflected in ways of practical interest to disease managers, particularly with respect to risk communication. Two manifestations of beliefs, attitudes, norms, and related risk perceptions that often surface are as follows:

- Stakeholder tolerance of the risks and impacts of wildlife diseases and the expectations of government to take action compared to stakeholder sense of self-efficacy to deal with potential impacts. Some of these impacts have to do with direct health and safety of wildlife, domestic animals, and humans. Some impacts are secondary, such as effects on viewing and hunting opportunities or tradeoffs between perceived risks compared to costs of taking action.

- Social acceptability of management interventions (that is, public willingness to allow government to pursue various actions to address wildlife disease concerns, such as culling). The effects of such interventions on wildlife viewing and hunting opportunities will influence acceptability of an intervention among some segments of society.

Social science research can provide insight into these practical considerations for wildlife disease managers. With such insight, managers can better judge when to take action, the outcomes desired/expected by various stakeholders, which individuals need an explanation as to why management is needed or not, and the extent and magnitude of resistance to management alternatives. Such knowledge should inform stakeholder engagement and risk communication.

\section{Many Ways to Gain Insight about Stakeholders-Which Is Best?}

When wildlife disease managers need to understand people's perceptions and behaviors regarding wildlife disease or disease management and managers turn to social science for assistance, the options and jargon can be daunting. Do not assume someone without training can design a survey and end up with a credible product. Surveys designed without expert assistance often do not provide the needed information and can lead to backlash from the target audience. Most wildlife disease practitioners do not have extensive social science research expertise, but an individual can become aware of the usual considerations for determining which research methods are appropriate in a particular situation. Even with minimal background, an individual can participate in planning a study by asking questions that will help to understand a social scientist's recommendations for research methods.

General references prepared especially as overviews and introductions of social science research methods for wildlife managers are as follows:

- Connelly, N.A., Siemer, W.F., Decker, D.J., and Allred, S.B., 2012, Methods of human dimensions inquiry, in Decker, D.J., Riley, S.J., and Siemer, W.F., eds., Human dimensions of wildlife management ( $2 \mathrm{~d}$ ed.): Baltimore, Md., Johns Hopkins University Press, p. 122-138.

- Decker, D.J., 2012, Planning a human dimensions inquiry, in Decker, D.J., Riley, S.J., and, Siemer, W.F., eds., Human dimensions of wildlife management $(2 \mathrm{~d}$ ed.): Baltimore, Md., Johns Hopkins University Press, p. 115-121.

Many other resources are available, as well. For example, the National Park Service (NPS) Rivers, Trails, and Conservation Assistance Program created "community tool boxes" that can assist in selecting tools for information gathering, facilitation, and other aspects of engagement (https://www. nps.gov/orgs/rtca/resources.htm). In addition, the National Conservation Training Center periodically offers a course on the "Human Dimensions Foundations of Natural Resource Conservation" (https://nctc.fws.gov/courses/descriptions/ CLM8226-Human-Dimensions-Foundations-of-NaturalResource-Conservation.pdf).

The main types of data collection and considerations for selecting among the types, are discussed in the next section. Specific resources are outlined in the section "Go it alone, or get some help?"

\section{Qualitative and Quantitative Methods-A Fork in the Road or Parallel Tracks?}

Social scientists usually take either a qualitative or a quantitative approach to collecting information about stakeholders. Qualitative methods delve into capturing details about how individuals and groups understand a disease and specifics that drive their behaviors (for example, why do ranchers follow practices that may place livestock at risk of disease transmission from wildlife?). This type of research uses methods that allow the stakeholders to tell the researcher what is important, which typically rely on interviews and other narrative techniques. In contrast, people often associate social science with quantitative methods, such as structured surveys administered by mail, internet or telephone. Quantitative techniques focus more on systematic probability sampling to characterize a human population; for example, a random sample of ranchers may be contacted to determine what percentage would favor a particular disease management action. 
Qualitative and quantitative methodologies approach research from different perspectives, therefore combining qualitative and quantitative methods can be especially effective for a comprehensive understanding of the people involved in a particular situation. Some of the key differences between the two methods are listed in table 1.

Table 1. Areas of focus for qualitative and quantitative research.

[The commonly recognized strengths and weaknesses of many of the specific techniques are summarized in Connelly and others (2012)]

\begin{tabular}{ll}
\hline \multicolumn{1}{c}{ Qualitative research } & Quantitative research \\
\hline An individual's experience & The variable in question. \\
Inductive & Deductive. \\
Emergent & Structured. \\
Holistic & Particularistic. \\
Depth & Breadth. \\
\hline
\end{tabular}

\section{Qualitative Methods-Exploration and Depth}

Qualitative methods are especially useful for gaining an in-depth understanding of why people think about disease or disease management in particular ways. Usually individuals are selected purposefully to ensure that information is being gathered from people with the depth of knowledge or experience necessary to provide thoughtful insights, not identified randomly to represent statistically a particular segment of society. This selection curbs generalizability of findings to a particular population, the familiar goal of quantitative studies. Qualitative methods are core for anthropologists and historians and can be used to answer questions such as the following:

- What aspects of the disease matter to the people who are affected by the disease?

- What has influenced public understanding of the disease with time?

- How do stakeholders want to be engaged in disease management?

- What are the reasons that members of the public do not follow advice from managers?

The most common types of qualitative techniques used in WDM are in-depth, minimally structured interviews and facilitated small-group processes. An interview guide usually is available to help the researcher direct the interviewee through a set of topics related to the research question. The questions may not always be asked in the same way or in the same order; the actual discussion will be determined by what is important to the interviewees and by the interviewees' experiences, much like a news correspondent interview. The researcher needs to be clear on the theoretical frameworks that are being investigated to know when to follow up on ideas or probe for further details, especially ideas that had not occurred to the research team but emerge as crucial to stakeholders.

Typically, the results of open-ended interviews are not intended to be reported as frequencies. Instead, descriptive passages from transcripts of interviews are organized around themes to identify patterns in responses. For example, in one wildlife disease study, in-depth interviews were used to investigate the history of public reactions to an outbreak that killed large numbers of birds and fish in northwestern Michigan (Evensen and others, 2013). Research revealed a shift in concerns away from human and pet health toward wildlife and environmental well-being during people's exposure to the hazard. This shift was attributed to factors that included clear science indicating low risks to human health, high levels of trust in local experts, collaboration among experts to present a clear and consistent message, and local interest in the environment. Although in-depth interviews can lead to new insights, effective coding and pattern identification takes practice and can be time-consuming, especially if the interviews are long.

The second most common qualitative approach, facilitated small group processes, includes techniques such as focus groups and nominal groups. Small groups of stakeholders from similar backgrounds are convened together to explore a topic, often to inform the design of a quantitative study (for example, help ensure validity of specific question wording and response categories used in questionnaires or structured interviews). Facilitated small group processes also have been used widely in wildlife management to reveal how stakeholders may react to specific proposals or to improve services offered by agencies. Skilled facilitators help make participants feel at ease and ensure that all participants have an equal opportunity to share their perspectives.

For example, focus groups were used in conjunction with content analysis to identify communication influences and needs of interpreters at NPS units threatened by WNS (Burnett, 2015). In 2015, WNS had been detected in or around 11 NPS units, leading to a study examining communication across parks. Focus groups with park staff and volunteers revealed a need for positive and empowering messages to ensure compliance with decontamination processes, messages and decontamination processes that were consistent but flexible enough to accommodate differences among parks, and increased awareness of materials and resources available from national NPS offices.

Small groups also have been used for participatory modeling, which examines the interactions between social and biological processes. Stakeholders are involved early in the process of conceptualizing how social-ecological systems function. Rather than have stakeholders comment on disease models developed by wildlife biologists and disease specialists, participatory models include from the outset the concerns of the people living with or interacting with wildlife on the ground. This type of modeling is based on anthropological, ethnographic, and participatory approaches and requires social 
science skills to be done well. Identifying the characteristics of phenomena like human well-being, which are important to parameterize and monitor from the social perspective, can be especially difficult for people accustomed to modeling natural science elements. Although few examples exist for WDM specifically, a growing cadre of researchers and practitioners from disciplines ranging from anthropology to natural resource management to human geography are leading participatory modeling efforts for natural resource management and conservation issues.

\section{Quantitative Methods-Structure and Numbers}

Most people are familiar with conventional quantitative survey methods - questionnaires received via the mail or the web, and interviews by telephone or face to face. If an individual is asked to participate in such surveys, the selection is generally random. Individuals usually will be asked to respond to a set of structured questions with preconstructed response options.

For these techniques, design of questions and response categories takes a great deal of skill to obtain good data and avoid threats to validity and reliability; for example, leading questions, double-barreled questions, or overlapping response categories. In addition, questions and response categories should be grounded in a good understanding of how potential respondents think about the issues, especially given that the public and experts often think about diseases differently. Do not assume to know what aspects of the disease the public is concerned about or why.

Quantitative methods are particularly useful to understand how widespread certain sentiments are, often measured in terms of quantity, amount, intensity, or frequency. Random sampling is used to ensure that results can be generalized across a population. The fields of sociology, psychology, and economics often rely on these methods to answer questions such as the following:

- How many people hold specific beliefs, attitudes, or risk perceptions about a disease?

- How much knowledge do people have about various aspects of the disease?

- To what degree does the community support or oppose specific management actions?

- How likely are people to engage in certain behaviors that mitigate or exacerbate disease risks or spread?

Three useful quantitative methods are structured surveys, social network analysis, and content analysis. Structured surveys are often the first method that people turn to when considering social science for WDM and can be implemented in multiple ways. Structured surveys can be implemented by face-to-face interviews, telephone interviews, mail surveys, or web-based surveys. All forms of implementation utilize a standardized questionnaire that asks questions of every participant in the same way. In addition, most questions are closed-ended, meaning that the participant must choose among specific response items. Common types of questions include the following: yes/no, checkboxes of categories (for example, asking respondents to select all activities they have participated in during a specific timeframe), or scales (for example, responses that range from none to a lot or from strongly agree to strongly disagree). Open-ended (write-in) questions are used sparingly as they are much more time consuming to analyze and difficult to interpret without being able to ask clarifying questions. Respondents are randomly selected from a predetermined sample frame that defines the population of interest. This type of selection allows researchers to identify the number of people to survey and the number of completed questionnaires needed to be able to generalize results. Occasionally response rates exceed 50 percent but, usually, only a small percentage of people respond, often as low as $20-40$ percent, necessitating persistent follow-up with a segment of those who do not respond to the survey to ensure that a concerning nonresponse bias does not exist.

Because of technology, participants can respond to surveys via a web-like interface on touchscreen devices, such as tablets, in the field. This approach was used in a study on communication about increased incidence of deadly bacteria (Vibrio) in oysters in the Pacific Northwest. Passengers entered survey responses on iPads while traveling on ferries between the San Juan Islands in Washington State (McComas and others, 2015; Schuldt and others, 2016). The study determined that messages focusing on human health and social aspects of marine diseases may increase public support for policies aimed at restoring ocean health, compared to those that focus on impacts to marine wildlife.

Social network analysis is a technique that quantifies the relationships and interactions among individuals or entities. Characteristics of relationships and interactions are analyzed for structural patterns that emerge among individuals or entities, how individuals or entities are positioned within a network, and how relationships are structured into overall network patterns. Social network analysis helps identify individuals who are "bridgers" between different social groups within a network and "bonders," those who are key to maintaining a subgroup's identity. Knowing how people are connected within networks can increase the efficiency of wildlife disease managers by directing their communication efforts towards key individuals or groups rather than less efficient broadcast approaches. Social network analysis is a new analytic tool for the human dimensions of wildlife management. The analysis is often completed as one component of a research program, because the results do not help understand traits or preferences of individuals or groups. Researchers anticipate that social network analysis will be useful in understanding stakeholder interactions regarding risk communication about wildlife disease. 
Content analysis is an analytic technique that allows the researcher to make inferences from texts and increasingly other types of materials such as images, audio, and video. These inferences are about the creators of the content, the message in the material, or the intended recipients of the message. Content analysis can be used for many purposes, including categorizing narrative responses to open-ended survey questions and public comments on a wildlife issue, analyzing interview transcripts, or describing trends in content of various kinds of communication about a wildlife disease issue. Content of mass media also can be analyzed to help wildlife disease managers understand how those media reflect public attitudes and influence public actions (for example, compliance with human-wildlife interaction advisories). Thematic codes are attached to the segments of text (or images or audio/ video segments) for easy retrieval and comparison. Coding is an iterative, qualitative process, but standards of practice exist to ensure reliability and replicability.

Content analysis is included in the quantitative section because when codes are attached to segments of text, they can be sorted and viewed together for emergent concepts, and the codes can be tabulated such that associations between themes can be compared statistically. Consistent coding of content across a large body of materials can be daunting. Research projects often include hundreds of news articles and thousands of pages of interview transcripts. Although multiple coders can be used to reduce the coding burden, achieving intercoder reliability to ensure all coders are applying the codes in the same way can be time consuming. Computer applications are being developed to automate some aspects of content analysis; for example, the ability to count the frequency of certain types of words across a dataset or time. This automation generally relies on having large datasets and a high degree of skill in computer programming. More and more of these applications are being developed, and this type of analysis is likely to play a larger role in understanding public sentiment to wildlife disease as these applications become more accessible and user friendly.

\section{Using Qualitative and Quantitative Methods in Combination}

Qualitative and quantitative methods can often be used together to complement one another. In studies about human dimensions of wildlife management, such mixed methods are used most often for the following three purposes:

- Developing a future study (for example, using qualitative methods to determine the focus of a future quantitative effort, including the specific questions and response items that are relevant to ask about).

- Complementing a previous study (for example, using a quantitative study to determine the degree to which in-depth insights from qualitative research can be generalized across a population).
- Triangulating one type of study with another to increase confidence in findings by corroborating the results.

For example, Kempton and Falk (2000) used a range of methods to examine mid-Atlantic residents' understanding and perceptions of risk related to Pfiesteria piscicida, a marine microorganism that kills fish and was first reported in 1992. In the late 1990s, well-publicized fish kills in Chesapeake Bay tributaries resulted in multimillion-dollar effects on the regional economy because people stopped buying seafood and participating in recreational fishing. However, most of the species and areas avoided were unaffected by Pfiesteria. Researchers were interested in understanding what led to this public reaction. Researchers first used qualitative semi-structured interviews of residents to uncover concepts important to the audience of interest that the researchers might not have known to ask about. Researchers also used a simple (threequestion) questionnaire followed by informal interviewing with attendees at a public event on coastal issues. The semistructured and informal interviews revealed that because this was a new pathogen, people used concepts they had experience with to understand how to respond to Pfiesteria. People thought about Pfiesteria as a fish disease, fish parasite, water pollutant, or toxin. These frames of reference, or "cultural models," did not align with those used by marine biologists (Pfiesteria as a predator that attacks fish) and appeared to influence inappropriate public reaction, even if people had been exposed to a lot of facts about the organism. This work was used to develop a four-page survey, which was administered to a random sample of residents in four states where $P f$ esteria outbreaks had occurred and two states where outbreaks had not occurred. The survey confirmed that most people relied on the cultural models identified in the qualitative research, not the model used by marine biologists. In addition, the cultural models were related to inappropriate inferences about pathways of harm and appropriate behavioral response. This information led to recommendations for developing communication efforts around a more accurate preexisting cultural model, such as a predator-like piranha or sea jelly, rather than focusing efforts on providing additional, factual information about the disease organism.

\section{Go It Alone or Get Some Help?}

Some of the research methods can be attempted by a novice seeking information about straightforward questions that describe the human population of interest, if careful attention is paid to the available "how to" guides that have synthesized the hard-learned conventions of each technique. Better yet, the novice can potentially elicit good information if advice and guidance are sought from experts when developing a survey or other data-gathering technique. Federal employees will need to be aware of the Paperwork Reduction Act (44 U.S.C. 3501 et seq.), which requires Office of Management and Budget review when information is collected systematically 
from 10 or more people who are not federal staff. Similarly, any research performed in conjunction with university partners or that may be published in peer-reviewed journals may be subject to Institutional Review Board approval for protection of human subjects. For guidance, consult with your agency's Office of Management and Budget coordinator or the university's Institutional Review Board, or both. Successful execution of a social science study by novices is not typical because, usually, the wildlife manager is looking for attitude and behavioral intention indices, which are not straightforward measures. The following is a list of resources that expand on the methods. These resources can help you determine whether professional assistance is needed, or whether to go it alone.

\section{Suggested Resources for Qualitative Methods}

- Lincoln, Y., and Guba, E.G., 1985, Naturalistic inquiry: Newbury Park, Calif., Sage Publications, 416 p.

- Miles, M.B., and Huberman, A.M., 1994, Qualitative data analysis (2d ed.): Thousand Oaks, Calif., Sage Publications, $338 \mathrm{p}$.

- Patton, M.Q., 2002, Qualitative research \& evaluation methods ( $3 \mathrm{~d}$ ed.): Thousand Oaks, Calif., Sage Publications, $688 \mathrm{p}$.

\section{Suggested Resources for Quantitative Methods}

- Dillman, D.A., Smyth, J.D., Christian, L.M., 2014, Internet, phone, mail and mixed-mode surveys-The Tailored Design Method (4th ed.): Hoboken, N.J., John Wiley $528 \mathrm{p}$.

- Kalton, G., 1983, Quantitative applications in the social sciences - Introduction to survey sampling: Beverly Hills, Calif., Sage Publications, 96 p.

- Salant, P., and Dillman, D.A., 1994, How to conduct your own survey: New York, Wiley, 256 p.

\section{Suggested Resources for Mixed Methods}

- Tashakkori, A., and Teddlie, C., 1998, Mixed methodology - Combining qualitative and quantitative approaches: Thousand Oaks, Calif., Sage Publications, $185 \mathrm{p}$.

\section{Engaging Stakeholders in Wildlife Disease Management}

Effectively engaging stakeholders in WDM includes many considerations. First, the approach to stakeholder engagement establishes the relationship between the natural resource management agency and stakeholders, as well as goals and expected outcomes of engagement. In addition, a wide variety of techniques for stakeholder engagement exist, and techniques are more effective when deliberately chosen based on approach. Stakeholder engagement in decision making differs from stakeholder engagement in research, although engaging stakeholders in research can play an important role in management. This section provides overviews and resources to assist in selecting among approaches to stakeholder engagement in decision making and appropriate techniques, as well as designing citizen science projects to engage stakeholders in research.

\section{Approaches to Stakeholder Engagement in Decision Making and Management}

The WDM model (fig. 1) encourages agency interaction with the public, consistent with growing recognition that wildlife management decisions are not isolated technical events, but a process of governance shared to varying degrees between managers and stakeholders. Interactive approaches that encourage deliberation among various stakeholders and managers are potentially valuable for revealing risk perceptions associated with a disease and acceptability of approaches to disease management. Initial stages of citizen participation also present opportunities to identify public information and educational needs (that is, content of risk communication). Thus, WDM includes many reasons to consider engaging stakeholders.

Stakeholder engagement processes can be designed with several of the following reasons in mind: improve managers' understanding of stakeholder concerns (including stakeholders internal to the organization and external publics and partners); improve stakeholders' understanding of concerns of the wildlife health community and reasons behind proposed actions; improve policy; and improve management response, especially when the public is required or expected to voluntarily take certain actions. Stakeholder engagement also can serve as additional audience research to identify concerns about diseases and their management and can benefit from previous audience research in their design. For example, audience research that has identified specific areas of disagreement or misunderstanding can help managers determine the topics that need greater involvement from stakeholders to identify ways to move forward.

Different approaches to engaging stakeholders in wildlife management have been deployed during the last several decades for the purposes of identifying objectives and actions for WDM. The approaches have been labeled as follows: inform, consult, involve, collaborate/seek consensus, and comanage (fig. 3), and associated characteristics are outlined in table 2. One or a combination of these approaches can facilitate stakeholder engagement in developing objectives and actions for WDM. A brief overview of the key differences in these approaches is provided using the example of viral hemorrhagic septicemia (VHS) in the Great Lakes region. VHS is a highly contagious, virulent virus that affects more 


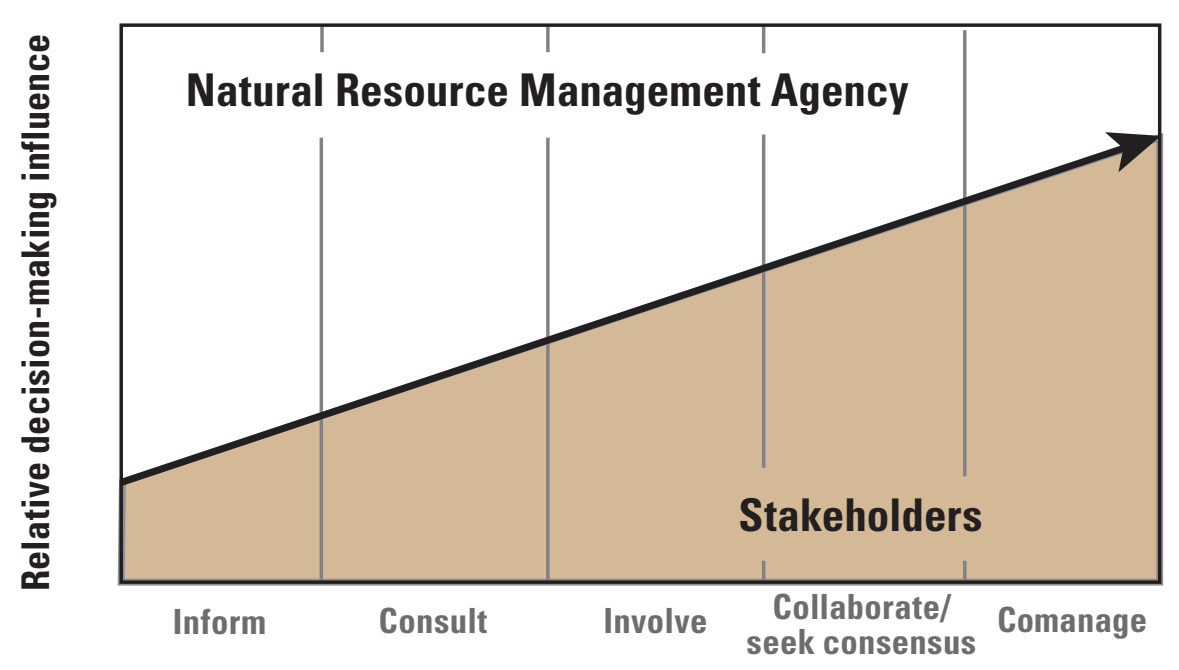

\section{Stakeholder engagement strategy}

Figure 3. Stakeholder engagement strategy and relative decision-making influence of stakeholders compared to the natural resource management agency. Figure modified from Clarke and Leong (2016).

than 80 species of freshwater and marine fish in the Northern Hemisphere. VHS has caused large-scale fish kills of species popular for sport fishing and as bait. Since VHS was first detected in the Great Lakes in 2005, managers have engaged stakeholders using a range of approaches.

Inform. - Inform represents a top-down approach to decision making, where the agency does not actively seek information from stakeholders, but rather seeks to keep stakeholders informed of agency actions. Feedback is not solicited, but is considered when received. This approach was once common in wildlife management; however, with time, societal expectations for governance and corresponding public administration legislation has shifted from simply informing the public about management decisions to more actively involving the public in the decision-making process. Although no longer standard practice from an overall governance standpoint, at times an inform approach is necessary. For example, in 2006, the rapid spread of VHS in the Great Lakes region led the U.S. Department of Agriculture Animal and Plant Health Inspection Service to issue an emergency federal order severely restricting the movement of fish. This federal order quickly established a mechanism to reduce the spread of VHS.

Consult and involve.-Consult and involve include active solicitation of stakeholder feedback. This approach can be achieved through a variety of techniques, such as public meetings, mail and web solicitations, and "ad hoc" citizen advisory committees, as well as methods outlined in the previous audience research section, including focus groups, nominal groups, and mail, telephone, and face-to-face interview surveys. Legal provisions for public input exists and are under the Administrative Procedure Act (5 U.S.C. 551 et seq.) and National Environmental Policy Act (42 U.S.C. 4321 et seq.), which have made public hearings a standard part of the decision-making process. The VHS federal order caused major disruptions to commercial and recreational fishing, aquaculture, and agency fishery programs, leading U.S. Department of Agriculture Animal and Plant Health Inspection Service to desire additional input from stakeholders. The U.S. Department of Agriculture Animal and Plant Health Inspection Service funded a study to characterize key stakeholder groups' concerns about and responses to VHS and its management to inform the design and implementation of VHS regulatory and educational efforts by state and federal agencies.

Collaborate/seek consensus and comanage.-Collaborate/seek consensus and comanage involve a still greater level of engagement. These approaches are particularly useful in situations that affect multiple partner organizations, local governments (communities), or stakeholder groups. A collaborate/seek consensus approach includes stakeholders in all steps of the decision-making process, including some authority for the decision itself. Groups of stakeholders convened by federal agencies may function as official advisory committees, although these groups can also provide input outside of the capacity of a formal committee. The Federal Advisory Committee Act (FACA, 5 U.S.C. App.) governs the establishment and operation of advisory committees, including many procedural requirements. Federal employees should consult with their Departmental Solicitors to determine whether the type of engagement they desire requires establishment of a FACA committee. Comanage goes one step further and relies on substantial engagement of citizens as individuals, communities, and nongovernmental organizations in most aspects of management implementation. Comanagement is not currently (2019) typical for federal agencies, although it is increasingly 
Table 2. Spectrum of approaches to stakeholder engagement in decision making. Shaded row indicates techniques to consider for each approach.

[Based on International Association of Public Participation Spectrum modified by Department of the Interior and Leong and others (2009). MOU, Memorandum of Understanding; MOA, Memorandum of Agreement]

\begin{tabular}{|c|c|c|c|c|}
\hline Inform & Consult & Involve & $\begin{array}{c}\text { Collaborate/seek } \\
\text { consensus }\end{array}$ & Comanage \\
\hline \multicolumn{5}{|c|}{ Agency goal } \\
\hline \multicolumn{5}{|c|}{ Agency commitment to stakeholders } \\
\hline $\begin{array}{l}\text { Agency will provide } \\
\text { stakeholders with } \\
\text { comprehensive, } \\
\text { accurate, and timely } \\
\text { information about its } \\
\text { decision making. }\end{array}$ & $\begin{array}{l}\text { Agency will keep stake- } \\
\text { holders informed, } \\
\text { listen to concerns } \\
\text { and suggestions, and } \\
\text { provide feedback } \\
\text { on how input was } \\
\text { considered in the } \\
\text { decision-making } \\
\text { process. }\end{array}$ & $\begin{array}{l}\text { Agency will work with } \\
\text { stakeholders to ensure } \\
\text { that their suggestions and } \\
\text { concerns are reflected } \\
\text { in the alternatives } \\
\text { developed during the } \\
\text { decision-making process } \\
\text { and provide feedback on } \\
\text { how input influenced the } \\
\text { decision. }\end{array}$ & $\begin{array}{l}\text { Agency will partner with } \\
\text { stakeholders at each } \\
\text { stage of the decision- } \\
\text { making process, seek } \\
\text { advice on the formula- } \\
\text { tion of the alternatives } \\
\text { and solutions, and } \\
\text { incorporate advice } \\
\text { and recommendations } \\
\text { into the decisions to } \\
\text { the maximum extent } \\
\text { possible. }\end{array}$ & $\begin{array}{l}\text { Agency will partner with } \\
\text { stakeholders at each } \\
\text { stage of the decision- } \\
\text { making process (as } \\
\text { outlined in collaborate/ } \\
\text { seek consensus column) } \\
\text { and will share responsi- } \\
\text { bility for decisions and } \\
\text { implementing actions } \\
\text { with stakeholders. }\end{array}$ \\
\hline \multicolumn{5}{|c|}{ Decision making } \\
\hline By agency & $\begin{array}{l}\text { By agency with oppor- } \\
\text { tunity for suggestions } \\
\text { or feedback }\end{array}$ & $\begin{array}{l}\text { By agency with stakeholder } \\
\text { input considered in } \\
\text { advance of decision }\end{array}$ & $\begin{array}{l}\text { Shared decision-making } \\
\text { process involving } \\
\text { agency and stakehold- } \\
\text { ers }\end{array}$ & $\begin{array}{l}\text { Shared decision-making } \\
\text { process, with stakehold- } \\
\text { ers as equal partners in } \\
\text { decision implementation. }\end{array}$ \\
\hline \multicolumn{5}{|c|}{ Possible issues } \\
\hline $\begin{array}{l}\text { Full and timely distribu- } \\
\text { tion and access. } \\
\text { Ability to respond to } \\
\text { questions. } \\
\text { One-way information } \\
\text { stream. }\end{array}$ & $\begin{array}{l}\text { Stakeholders do not } \\
\text { actually shape } \\
\text { decision. } \\
\text { Forums/processes } \\
\text { can be formal/ } \\
\text { mechanistic (Federal } \\
\text { Register), not con- } \\
\text { ducive for genuine } \\
\text { dialogue and public } \\
\text { involvement. }\end{array}$ & $\begin{array}{l}\text { Raised expectations. } \\
\text { Are all interests involved? }\end{array}$ & $\begin{array}{l}\text { Federal Advisory Com- } \\
\text { mittee Act concerns. } \\
\text { Are all interests involved? } \\
\text { Is issue ripe/ready for } \\
\text { collaboration? } \\
\text { Time constraints. } \\
\text { Resources required. }\end{array}$ & $\begin{array}{l}\text { Fundamentally different } \\
\text { approach where agency } \\
\text { is a participant in deci- } \\
\text { sion making, not the sole } \\
\text { decision maker, which } \\
\text { may be uncomfortable } \\
\text { to some. } \\
\text { Challenging to coordinate } \\
\text { multiple entities that } \\
\text { historically exercised } \\
\text { independent decision- } \\
\text { making authority. }\end{array}$ \\
\hline
\end{tabular}

${ }^{1}$ Cumulative from left to right; each column includes all options in columns to the left. 
being used by state agencies. In addition, comanagement is also used in large landscape collaborations, where no single entity (for example, agency, organization, local government, and private landowner) is the primary decision maker, but all are partners and have influence on aspects of the management decision. For VHS, staff from state and federal agencies across the Great Lakes Basin are working together to increase the effectiveness of their efforts to slow the spread of fish pathogens and aquatic invasive species. The staff have engaged with each other through a variety of collaborative bodies (such as task forces and panels) to try to increase the consistency of their regulations and recommendations.

The development of these approaches to stakeholder engagement are presented in the order in which the approaches historically emerged, which corresponds to innovations in methods to increase the degree of stakeholder engagement and empowerment. This order of presentation does not mean that only a comanage approach should be applied today. On the contrary, as demonstrated with the VHS example, each approach may be appropriate even within the same management issue, depending on the specific engagement context, goals, and target publics. Factors that can help determine which approach to use are outlined in table 2 .

\section{Stakeholder Engagement Techniques}

Many techniques are available to wildlife disease managers who want to involve stakeholders in management planning (see the "Techniques to Consider" section of table 2). The selection of a tool for this purpose is based on several considerations, because each tool has advantages and disadvantages. A variety of resources are available to help managers decide which stakeholder engagement tools to use, based on the stakeholder's goal for participation. Often, managers detail how various tools are applied and describe the pros and cons of each. The NPS Rivers, Trails, and Conservation Assistance Program community tool boxes (https://www.nps. gov/orgs/rtca/resources.htm) are one example. In addition, the National Oceanic and Atmospheric Administration (NOAA) Office for Coastal Management produced a helpful guide that includes advantages and limitations for many of the common stakeholder participation techniques (https://coast.noaa. gov/data/digitalcoast/pdf/stakeholder-participation.pdf). The Environmental Protection Agency has compiled a wide range of resources (https://www.epa.gov/international-cooperation/ public-participation-guide-internet-resources-public-participation), including the IAP2 Public Participation Toolbox, which lists a variety of stakeholder engagement techniques, including considerations of what can go right and what can go wrong.

\section{Stakeholder Engagement in Research}

In addition to engaging stakeholders in decision making, a movement to involve the public in science, termed "citizen science," is growing. Citizen science is where laypeople - citizens - are meaningfully engaged in some aspect of research about the biology or human dimensions of a wildlife disease or health promotion program. Although not common practice, managers are increasingly engaging stakeholders in research through citizen science projects. Many projects, such as the Audubon Society's well-known Christmas Bird Count, are designed to involve nonscientists in collecting scientific data. Others involve citizens in identifying specimens or other aspects of the scientific process. The projects promote public engagement in science and contribute to conservation. A citizen science project associated with a wildlife health/ disease management program might encourage volunteers to participate in the fieldwork needed to detect a disease and assess disease prevalence and distribution. For example, Cornell Lab of Ornithology and Bird Studies Canada are enlisting private citizens to monitor house finch eye disease, or Mycoplasma conjunctivitis, at birdfeeders (for more information, see the following project website: https://feederwatch.org/ learn/house-finch-eye-disease/). Although this kind of involvement is not a substitute for input in decision making, such involvement can increase the knowledge of citizens who engage in both aspects of a management program. The involvement also helps managers develop relationships and build trust with the community of citizen science volunteers. The U.S. General Services Administration and the Citizen Science Association have developed toolkits available at https://www.citizenscience. gov/toolkit/\# and at https://www.citizenscience.org/.

\section{Go It Alone or Get Some Help?}

Individual managers and their organizations have varying degrees of skill and capacity for stakeholder engagement. Determining what should be attempted alone versus when to get help from partners or contractors is difficult. If a manager does not have experience with stakeholder engagement, the manager should speak to someone who is a specialist and determine, with their input, whether to go it alone or get some help. Seeking partners or contractors who have expertise in techniques of engagement and experience applying these techniques across a range of situations is usually advisable. Specialists may be working in university departments of planning or as practitioners who specialize in alternative dispute resolution, public participation, or conflict transformation. Some resources include the International Association for Public Participation https://www.iap2.org/mpage/Home), U.S. Institute for Environmental Conflict Resolution (http:// www.udall.gov/ourprograms/institute/institute.aspx), and the U.S. Department of the Interior's Office for Collaborative Action and Dispute Resolution (https://www.doi.gov/pmb/ cadr/). The U.S. Institute for Environmental Conflict Resolution and the U.S. Department of the Interior's Office for 
Collaborative Action and Dispute Resolution have indefinite delivery/indefinite quantity contracting vehicles that can be used by federal agencies to access professional assistance and contact information for practitioners across the United States.

\section{Suggested Resources for Stakeholder Engagement}

- Environmental Protection Agency, 2018, International Cooperation Public Participation Guide - Internet Resources on Public Participation: accessed July 22, 2019, at https://www.epa.gov/international-cooperation/public-participation-guide-internet-resourcespublic-participation.

- Lauber, T.B., Decker, D.J., Leong, K.M., Chase, L., and Schusler, T., 2012, Stakeholder engagement in wildlife management, in, Decker, D.J., Riley, S.J., and Siemer, W.F., eds., Human dimensions of wildlife management ( $2 \mathrm{~d}$ ed.): Baltimore, Md., Johns Hopkins University Press, p. 139-157.

- Leong, K.M., Decker, D.J., Lauber, T.B., and Chase, L., 2012, Stakeholders as beneficiaries of wildlife management, in, Decker, D.J., Riley, S.J., and Siemer, W.F., eds., Human dimensions of wildlife management $(2 \mathrm{~d}$ ed.): Baltimore, Md., Johns Hopkins University Press, p. 26-41.

- National Oceanic and Atmospheric Administration (NOAA) Office for Coastal Management, 2015, Introduction to Stakeholder Participation, $20 \mathrm{p}$ : accessed July 22, 2019, at https://coast.noaa.gov/data/ digitalcoast/pdf/stakeholder-participation.pdf.

\section{Risk Communication-Inspiring Risk-Wise Behavior}

How (content and method) and when (timing) WDM professionals speak and write about wildlife disease affects how the public thinks about and responds to risks, which can in turn affect the prevalence of infection (fig. 1). With the rising conservation and public health significance of wildlife diseases and commensurate elevated public profile of WDM, communication to create realistic risk perceptions and appropriate responses has never been more critical. Like stakeholder engagement, a large body of work has identified some of the most important characteristics of successful risk communication. Following these guidelines can help ensure that communication efforts do not inadvertently cause an unintended reaction. The primary goal of risk communication is to help people understand risk and make decisions that keep themselves, their families, pets and domestic animals, and wildlife as safe as possible. Management actions can target wildlife workers (see chapter $\mathrm{C} 2$ of this field manual, Buttke and Taylor, in press), but risk communication also is used to influence behavior more broadly. In this section, risk perceptions are connected with communication strategies, based on a handbook developed by the NOAA Office for Coastal Management (2016) and revised with permission to focus on wildlife disease. As the handbook indicates, understanding what not to do is a good place to start.

\section{Do Not Do This}

Social science researchers have determined that two approaches commonly applied by people and organizations are often the most ineffective - providing people who seem unreceptive with more and more information and invoking fear or anxiety without offering realistic and actionable solutions.

\section{Do Not Provide More Information without Action}

People often assume that others feel and think the same way they do, and that whatever information is meaningful for one person will be meaningful for all people. For example, despite decades of messaging about interacting with wildlife, people continue to approach and feed animals and, therefore, put the animals at risk of injury and disease. These interactions arise for many reasons. For example, some people may think the risk does not apply to them, or the thrill of being close to a wild animal is worth the risks, or that the threat is being overplayed by managers.

Simply providing more information about a risk will not work. In discussing risks - especially disease risks from wildlife - communicators should highlight what is important to individuals and what should be done to address the risk. Communicators should not assume everyone agrees with the same solutions, that every solution is realistic for everyone, and that making decisions to reduce a risk is a simple mental process.

\section{Do Not Invoke Fear and Anxiety}

People worried about diseases from wildlife often assume that sharing their emotions will spur others to take action. These people tend to use dread or fear as the dominant theme in their message. But people can only worry about so many things at one time. Invoking fear, dread, or anxiety as the sole theme of the message - without discussing concrete and realistic ways to reduce the risk - frequently causes others who do not feel the same way to shut down, tune out, or fear the wildlife species itself rather than the disease. For example, when discussing how rabies will affect bat populations, using dramatic language and imagery of the aftermath of an outbreak may reflect the communicator's emotions and feelings. But this same information can overwhelm others, making them feel helpless about their ability to prepare for the risk, or reinforcing societal stigmas against bats (Lu and others, 2017). Instead, use language that is more neutral, and if messages emphasize bats as the source of the disease, include information about the benefits of bats to avoid unintended negative consequences for bat conservation. In addition, including information that indicates how people can protect themselves from contracting rabies from bats can reduce feelings of helplessness and help turn fearful emotions into realistic actions. 


\section{Communication Tip}

\section{Make It Local, Not About the Science}

Chances are that readers of this field manual work in WDM and consider the science and technical details about wildlife disease risk compelling. However, others may not receive this information in the same way. One way to overcome this discrepancy is to focus on what people can observe, such as animals that are sick or behaving strangely. Focusing on what people have observed is a way to bring the message closer to home, which makes the impacts real and personal and avoids a debate about technical details.

\section{Do This Instead}

To inspire risk-wise behavior, communicators must work to overcome communication hurdles. So, what does work?

Remember that minds and behaviors do not change overnight. No magic words and no perfect phrases can inspire risk-wise behavior. Risk communication research has continually indicated that people gradually change their minds and behaviors when presented with information that affirms how they view the world and what they already believe. The results of this research do not indicate that people should be told what they already know, but rather people should be listened to carefully to understand their worldview and what matters to them. Multiple trusted sources must present the information, and the information must be repeated often. Information also must be paired with realistic actions and solutions. Effective risk communication efforts use an approach that allows a diverse set of stakeholders to explore risk and identify appropriate solutions together, while addressing the emotions and values that influence response. This approach takes time to learn and plenty of practice.

The following is a list of a few key steps to take when engaging in a conversation with the public about risks.

- Recognize how individuals perceive risks and why those perceptions affect their actions. Identify what is behind the other person's point of view.

- Learn what the audience values and how these values influence risk perception. Understand what the audience cares about.
- Shape or frame the message to affirm the values of those receiving the message. Frame the conversation to meet individual needs.

Not every communication situation is the same. Some one-on-one interactions and conversations with small groups have members with different worldviews and values. Sometimes the situation is a one-time conversation, and other times the situation is a continuing dialogue. Addressing these situations requires different methods, but several best practices are available for risk communication that are important for all types of engagement.

\section{Get to Know the Audience}

Communicators cannot craft an effective message if they do not know the audience and what matters to that audience. Learn who the audience is, what the audience cares about, and what challenges the audience may face in addressing risks. Refer to the section on audience research for ideas and approaches. Working with social scientists would be ideal to gather this information. Even if a context-specific study is not possible, some things can be done. For example, when speaking with a group, ask questions before or even during the presentation through various facilitation techniques, such as instant polling. If talking with someone one-on-one, listen actively and ask good questions to learn about the person and make better decisions about how to communicate with that person.

\section{Communication Tip}

\section{Stories Make a Difference}

Stories, examples, and even relevant metaphors are learning tools. Stories help information become real and relevant, allowing people to see the effects of a potential risk. However, select examples that are appropriate and realistic to the audience and refrain from overdramatizing.

\section{Know the Goal}

Have an action-oriented goal that identifies the desired behavior change. The goal may be to help people visiting caves to understand how cleaning their equipment and shoes helps prevent the spread of WNS in bats, or to educate people about the disease transmission risks associated with feeding wildlife. Identifying these goals helps communicators determine how to proceed. 


\section{Develop a Communication Plan}

Knowing the audience and goal are crucial first steps. Identify the approach for discussing the risk, the tone, relevant solutions, and responses to potentially challenging questions. Having a good plan helps presenters deliver the message effectively and reach the risk communication goals.

\section{Explain the Risk in a Manner that is Clear and Appropriate}

Talking about risks using technical terms can be a recipe for misunderstanding; therefore, discuss risks in a way that resonates with the audience. Focus on local and observable impacts, because those impacts make the risk tangible and real. Acknowledge what is known and unknown when responding to questions. Avoid overloading the audience with too much information at one time.

\section{Speak to the Audience's Interests, Not Yours}

Different audiences have different interests when discussing managing animal diseases. Hunters primarily are interested in harvest. Livestock producers are interested in health and economic impact of disease on production. Conservationists are interested long-term maintenance of native wildlife populations. The public is often more concerned with risks to human or pet health. Use audience research to learn what an audience specifically cares about. Frame the conversation to connect these interests with the overall risk messages.

\section{Offer Realistic and Appropriate Solutions and Options}

Information without specified actions leads to inaction. Pairing information about risks with ways people can respond is critical. This approach can be challenging because some actions may not be appropriate or feasible for some audience members. Invite stakeholders into a conversation about things they can do and even work together to identify potential responses.

\section{Develop and Deliver the Right Message}

Crafting the right message is not easy, but knowing the goals and the audience will help immensely. Make sure to test the message or product with members of the actual audience before expanding the effort. Just like market research for advertising, a focus group can be used or people can be interviewed to get their reactions to the message and what they take away from the message. These answers help modify the message to ensure that others will understand and correctly interpret what is being said. Recognize that people have different preferences for receiving information. Some people like to attend meetings or presentations, some people prefer a letter or email, and some people do not use the internet or have a cell phone. Use multiple methods of communication and keep messages consistent.

\section{Communication Tip} Talking About Uncertainty

When discussing future impacts, scientists and engineers often discuss the level of uncertainty. Someone trained in math and science thinks about uncertainty in terms of what they know. Most others hear uncertainty and think about what they do not know. Avoid using the word "uncertainty" whenever possible because it could undermine the argument. The words "could" and "may," when used to discuss a negative impact, can introduce doubt and cause people to unconsciously focus on the small probability that something might not happen.

\section{Use Trusted Messengers}

Trust is an essential component of effective communication. Find out who the audience already turns to for trusted information. Delivering the message repeatedly and through a variety of trusted sources helps the audience accept and internalize the information and gradually change behavior. Make sure everyone is on the same page if using messengers from multiple organizations. One note about trusted messengers and partners is that building trust with an audience may take a substantial amount of time, especially when a history of distrust exists. Trust can be damaged easily and is difficult to rebuild.

\section{Respect Different Viewpoints and Acknowledge Emotions}

Learning about risks can trigger strong emotions. Some people may have strong opposing views on risks and solutions. Therefore, respect everyone's viewpoint and acknowledge emotions as they arise. Stay positive and do not be dismissive. Let people know they are not alone in how they feel. When discussing emotionally challenging topics - such as how to manage the effects of toxoplasmosis from outdoor cats on sea otters, monk seals, and other wildlife - help the audience understand what can and cannot be done in a particular situation and what realistic expectations are for addressing the health concerns. For example, many arguments may focus on the value of wildlife compared to cats; however, all parties share a concern about animals' lives. By identifying core common ground, communities can work together to help the affected people make decisions for their future. 
In the end, people must be engaged in respectful conversations as part of an ongoing dialogue. Depending on the topic, the consequences of management for the other person, and the other person's values, these conversations may be uncomfortable. Yet, encouraging open discussion and respectful debate with people who hold different views creates an environment of openness. This type of discussion helps build trust, especially for people who may already feel that they are shut out of a conversation and are not being heard.

\section{Communication Tip}

\section{Words Matter}

Each person has a unique vocabulary. Some words are understood by peers in the same profession, but the same words are not understood by laypeople. Therefore, be careful about using jargon and too many technical terms. A good exercise to try is to explain your job to a family member. Think about the words used to explain your job. Ask the family member to let you know what they do not understand.

\section{Communicating with the Audience}

Understanding the audience is an obvious linchpin for success, and this background information should not be taken for granted. Aside from social science research, conversation with the target audience, with lots of patient listening, is one of the best ways to obtain a sense of their values and perspectives. For wildlife disease issues that affect residential communities, consider using the following conversation starters to obtain good information about the target audience.

\section{Experiences with Wildlife}

- Do you see much wildlife around your home? Your neighborhood?

- What do you think makes the area around your home attractive to wildlife? What draws wildlife to your home or nearby area?

- Which species do you enjoy the most?
- What are the positives and negatives about having wildlife living so close to your home?

- What do you do to attract or deter wildlife from coming near your home? What do your neighbors do?

\section{Reactions to Wildlife Disease}

- Do you worry about any diseases related to wildlife in your neighborhood? Which diseases and wildlife species?

- What would you do if a sick animal wandered into your neighborhood? Who would you contact?

- How do the benefits of having wildlife in your neighborhood compare to the costs, including any worries about disease?

\section{Framing the Conversation}

When information about the audience is known, the communicator can frame the conversation to connect with personal core values. The following messages provide examples of key general message frames, applied to homeowner concerns about raccoons and rabies.

\section{Be Prepared—Be Prepared to Avoid Contact with Wildlife or between Domestic and Wild Animals}

This empowering message appeals to a broad audience. A specific message is to be prepared to protect yourself and your pets from coming into contact with raccoons in the neighborhood.

Most receptive audience: All worldviews. Individualfocused people see this message as a call to take care of themselves, whereas community-focused people view this message as a way to help the community at large. Make sure the steps the audience can take to prepare themselves are included in the conversation.

\section{Personal Responsibility—Everyone Needs to Be Responsible for Their Choices and Actions}

This type of approach appeals to people who believe in fewer regulations and restrictions. Highlight the importance of people being responsible for themselves, their decisions, and their property. For example, homeowners can secure their trash so they do not attract raccoons and, thereby, reduce their exposure to raccoons that might carry rabies.

Most receptive audience: People who value individualism. People who value hierarchy, authority, and certainty likely value personal responsibility as well. 


\section{Stewardship-Good Stewards Protect the Planet}

Highlight that today's stewardship affects future generations by leaving the community and the world a better place. This approach focuses more on future risks, which would include messages such as support oral rabies vaccination of raccoons and do not attract raccoons to your backyard to reduce the risk of future disease outbreaks.

Most receptive audience: People who value environmentalism and are community-focused.

Some environmental issues can be politically polarizing. When talking to someone who does not value environmentalism, avoid terms such as eco, green, saving the planet, or ecosystem.

\section{Working Together-Communities Working Together Can Reduce Risks from Wildlife Disease}

Highlight why working together as a community helps to accomplish the task of reducing risk from wildlife disease. Although individual homeowner behavior can help reduce risks, community-wide support is necessary to prevent raccoons from being attracted to neighborhoods in search of trash.

Most receptive audience: People who are community and egalitarian focused.

\section{Go It Alone, or Get Some Help?}

The information in this section will help make risk communication efforts more successful. Presenting the same facts repeatedly does not represent effective risk communication. Communicators need to understand why people respond or behave the way they do and how people's minds sometimes work against their own best interests when perceiving risk. Understanding these dynamics can help wildlife disease managers be strategic in their communications, with the ultimate payoff being lower rates of disease and wildlife management efforts that enjoy strong community support. Although no perfect communication exits that will automatically change people's minds, audiences are more likely to hear and respond to messages that highlight what matters to them, affirm what they believe, and provide realistic and appropriate paths for addressing the risk. Using a variety of trusted sources to deliver the message helps people overcome mental barriers and recognize personal risks and impacts. Change does not come overnight or after a single interaction. Good risk communication is an ongoing process, and the approach used may change as more is learned about the audience, as relationships grow with partners, and as experienced is gained in framing messages that inspire the intended behaviors. Practice will help master these methods.
An individual may be more comfortable with some approaches compared to others, or partners may be available to help with an approach. Because everyone communicates, people often forget that risk communication is a specialized discipline. Seek input from specialists to affirm that the approach is on the right track, or to learn about alternative approaches that may improve communication efforts. Specialists work in departments of communication or journalism, and they may team with practitioners who specialize in message design and evaluation. Additional resources can also help determine how much assistance is needed. Peter Sandman's website summarizes many risk communication principles using the heuristic Risk = Hazard + Outrage (where hazard refers to the measurable physical consequences of the disease and outrage refers to the emotional and value-based factors) http://psandman.com/index-intro.htm. An especially useful article is Risk Communication: Evolution and Revolution, by Covello and Sandman (2001), http://psandman.com/articles/ covello.htm. The following is a list of books that cover various aspects of communication for effective WDM.

\section{Suggested Resources for Risk Communication}

- Hayes, R., and Grossman, D., 2006, A scientist's guide to talking with the media: New Brunswick, N.J., Rutgers University Press, 222 p.

- Jacobson, S. 2009, Communication skills for conservation professionals ( $2 \mathrm{~d}$ ed.): Washington, D.C., Island Press, 480 p.

- McKenzie-Mohr, D, 2011, Fostering sustainable behavior-An introduction to community-based social marketing (3d ed.): Gabriola, B.C., Canada, New Society Publishers, 171 p., accessed July 22, 2019, at: http://www.cbsm.com/pages/guide/preface/

- Shanahan, J.E., Gore, M.L., and Decker, D.J., 2012, Communication for effective wildlife management, in, Decker, D.J., Riley, S.J., and Siemer, W.F., eds., Human dimensions of wildlife management ( $2 \mathrm{~d}$ ed.): Baltimore, Md., Johns Hopkins University Press, p. 157-173.

- National Oceanic and Atmospheric Administration (NOAA) Office for Coastal Management, 2016, Risk communication basics: NOAA, 18 p., accessed July 22, 2019, at https://coast.noaa.gov/data/digitalcoast/ pdf/risk-communication-basics.pdf. 


\section{Summary and Conclusion}

The human dimensions of wildlife disease management (WDM) are complex and ever-present. At minimum, the wildlife disease manager should be cognizant of basic social science techniques to understand public sentiment, design effective stakeholder engagement processes and risk communication messages, and become familiar with available sources of assistance in these areas.

Although the literature is growing, little is known about human beliefs, attitudes, and risk perceptions with respect to wildlife disease or management of wildlife disease. The lack of generalizable insights specific to the human dimensions of WDM contributes to the difficulty of predicting people's responses to a disease management situation. This situation suggests the possibility that wildlife managers and disease specialists, in the absence of insight based on a trove of social science or extensive experience with stakeholder engagement, must make assumptions about stakeholder beliefs and attitudes. To the extent assumptions versus facts are relied upon, management decisions and actions might create an unnecessarily high probability of unintended impacts. In situations where wildlife diseases arise, this possibility can be minimized if concerned wildlife managers and social scientists collaborate to provide information that can inform WDM decision making. Or, better yet, negative collateral effects might be partially avoided in situations where a robust approach to WDM includes contingency planning that has a strong, proactive risk communication component.

Although an individual may not be an expert in the everpresent human dimensions of the social-ecological system within which a disease incident/outbreak is occurring, the individual can take steps to carefully consider those dimensions. In particular, expertise is available to help develop social science research, stakeholder engagement, and risk communication. This expertise may be available within an organization, among partners, or for hire.

\section{References Cited}

Aguirre, A.A., Longcore, T., Barbieri, M., Dabritz, H., Hill, D., Klein, P.N., Lepczyk, C., Lilly, E.I., McLeod, R., Milcarsky, J., Murphy, C.E., Su, C., VanWormer, E., Yolken, R., and Sizemore, G.C., 2019, The one health approach to toxoplasmosis: epidemiology, control, and prevention strategies: EcoHealth, v. 16, no. 2, p. 378-390. [Also available at https://doi.org/10.1007/s10393-019-01405-7.]

Bradley, C.A., Gibbs, S.E.J., and Altizer, S., 2008, Urban land use predicts West Nile virus exposure in songbirds: Ecological Applications, v. 18, no. 5, p. 1083-1092, https:// doi.org/10.1890/07-0822.1.
Burnett, K.C., 2015, Research, Development, and Evaluation of a public outreach communication plan and products for resource management and wildlife issues: Fort Collins, Colo., Colorado State University Department of Journalism and Media Communication, M.S. Thesis in Public Communications and Technology, $75 \mathrm{p}$.

Buttke, D.E., and Taylor, T., in press, Safe work practices for working with wildlife: U.S. Geological Survey Techniques and Methods, book 15, chap. C2, 26 p., https://doi.org/10.3133/tm15c2.

Clarke, M.M., and Leong, K.M., 2016, Building capacity for civic engagement and natural resource management in the National Park Service: Fort Collins, Colo., National Park Service, Natural Resource Report NPS/NRSS/BRD/NRR2016/1292, 28 p.

Clegg, S.R., Mansfield, K.G., Newbrook, K., Sullivan, L.E., Blowey, R.W., Carter, S.D., and Evans, N.J., 2015, Isolation of digital dermatitis treponemes from hoof lesions in wild North American elk (Cervus elaphus) in Washington State, USA: Journal of Clinical Microbiology, v. 53, no. 1, p. 88-94, https://doi.org/10.1128/JCM.02276-14.

Connelly, N.A., Siemer, W.F., Decker, D.J., and Allred, S.B., 2012, Methods of human dimensions inquiry, in Decker, D.J., Riley, S.J., and Siemer W.F., eds., Human dimensions of wildlife management ( $2 \mathrm{~d}$ ed.): Baltimore, Md., Johns Hopkins University Press, p. 122-138.

Covello, V., and Sandman, P.M., 2001, Risk communicationEvolution and revolution, in, Wolbarst, A., ed., Solutions to an Environment in Peril: Baltimore, Md., Johns Hopkins University Press, p. 164-178, http://psandman.com/articles/ covello.htm.

Decker, D.J., Jacobson, C.A., Forstchen, A.B., and Siemer, W.F., 2017, Moving wildlife conservation forward-Let's get real about relevancy, in Coon, R.A., and Dunfee, M.C., eds.: Gardners, Pa., Wildlife Management Institute, Transactions of the 82nd North American Wildlife and Natural Resources Conference, March 5-10, 2017, Spokane, Washington, p. 34-41.

Decker, D.J., Wild, M.A., Riley, S.J., Miller, M.M., Leong, K.M., Powers, J.G., and Rhyan, J.C., 2006, Wildlife disease management-A manager's model: Human Dimensions of Wildlife, v. 11, p. 151-158, https://doi. org/10.1080/10871200600669908.

Evensen, D.T.N., Decker, D.J., and Stedman, R.C., 2013, Shifting reactions to risks - A case study, Journal of Risk Research, v. 16, no. 1, p. 81-96, https://doi.org/10.1080/136 69877.2012.726238. 
Friend, M., 2015, Introduction, in Franson, J.C., Friend, M., Gibbs, S.E.J., and Wild, M.A., eds., Field manual of wildlife diseases: U.S. Geological Survey Techniques and Methods 15-A1, 10 p., https://dx.doi.org/10.3133/tm15a1.

Heberlein, T.A., 2004, Fire in the Sistine Chapel-How Wisconsin responded to chronic wasting disease: Human Dimensions of Wildlife, v. 9, no. 3, p. 165-179, https://doi. org/10.1080/10871200490479954.

Jakob-Hoff, R.M., MacDiarmid, S.C., Lees, C., Miller, P.S., Travis, D., and Kock, R., 2014, Manual of procedures for wildlife disease risk analysis: Paris, World Organisation for Animal Health, 160 p. Published in association with the International Union for Conservation of Nature and the Species Survival Commission.

Kasperson, R.E., 1992, The social amplification of risk-Progress in developing an integrative framework, in Krimsky, S. and Golding, D., eds., Social theories of risk: Westport, Conn., Praeger Publishers, p. 153-178.

Kempton, W., and Falk, J., 2000, Cultural models of Pfiesteria-Toward cultivating more appropriate risk perceptions: Coastal Management, v. 28, no. 4, p. 273-285, https://doi. org/10.1080/08920750050133548.

Leong, K.M., Decker, D.J., Lauber, T.B., Raik, D.B., and Siemer, W.F., 2009, Overcoming jurisdictional boundaries through stakeholder engagement and collaborative governance-Lessons learned from white-tailed deer management in the U.S., in Andersson, K., Eklund, E., Lehtola, M., and Salmi, P., eds., Beyond the rural-urban divide - Crosscontinental perspectives on the differentiated countryside and its regulation: Bingley, Emerald Group Publishing, p. 221-247.

Lu, H., McComas, K.A., Buttke, D.E., Roh, S., Wild, M.A., and Decker, D.J., 2017, One Health messaging about bats and rabies - How framing of risks, benefits and attributions can support public health and wildlife conservation goals: Wildlife Research, v. 44, no. 3, p. 200-206, https://dx.doi. org/10.1071/WR16061.

McComas, K.A., Schuldt, J.P., Burge, C.A., and Roh, S., 2015, Communicating about marine disease - The effects of message frames on policy support: Marine Policy, v. 57, p. 45-52, https://doi.org/10.1016/j.marpol.2015.02.012.
Meine, C., 2010, Aldo Leopold-His life and work: Madison, Wis., The University of Wisconsin Press, 672 p.

Morgan, M.G., Fischhoff, B., Bostrom, A., and Atman, C.J., 2002, Risk communication-A Mental Models Approach: New York, Cambridge University Press, 351 p.

National Academies of Sciences, Engineering, and Medicine, 2017, Communicating science effectively-A research agenda: Washington, D.C., The National Academies Press, $137 \mathrm{p}$.

National Oceanic and Atmospheric Administration (NOAA) Office for Coastal Management, 2016, Risk communication basics, 18 p.: accessed July 22, 2019, at https:/coast.noaa. gov/data/digitalcoast/pdf/risk-communication-basics.pdf.

National Park Service, 2014, A comprehensive review of National Park Service ungulate management-Second century challenges, opportunities, and coherence: Fort Collins, Colo., National Park Service, Natural Resource Report NPS/NRSS/BRMD/NRR—2014/898, 66 p.

Sandman, P.M., 1987, Risk communication-Facing public outrage: U.S. Environmental Agency Journal, v. 13, p. 21-22.

Schuldt, J.P., McComas, K.A., Byrne, S.E., 2016, Communicating about ocean health-Theoretical and practical considerations: Philosophical Transactions of the Royal Society B, v. 371, no. 1689, 9 p., http://dx.doi.org/10.1098/ rstb.2015.0214.

Slovic, P., Fischhoff, B., and Lichtenstein, S., 1979, Rating the risks: Environment, v. 21, no. 3, p. 14-39, https://doi.org/10 .1080/00139157.1979.9933091.

Wobeser, G.A., 1994, Investigation and management of disease in wild animals: New York, Plenum Press, 265 p., https://doi.org/10.1007/978-1-4757-5609-8.

Zarefsky, D., 1994, Public sentiment is everything-Lincoln's view of political persuasion: Michigan Publishing, Journal of the Abraham Lincoln Association, v. 15, no. 2, p. 23-40. 
Publishing support provided by the U.S. Geological Survey Science Publishing Network, Madison and Rolla Publishing Service Centers

For additional information contact;

Director, National Wildlife Health Center

U.S. Geological Survey

6006 Schroeder Road

Madison, WI 53711-6223

https://www.usgs.gov/centers/nwhc 



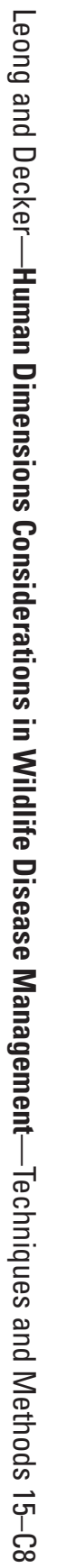

